\title{
Fasting in Ramadan and Diabetes
}

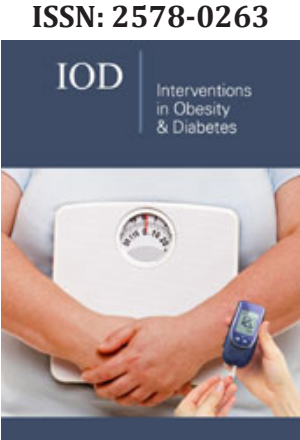

*Corresponding author: Zia Ashraf, College of Allied Health Professionals, Faisalabad, Pakistan

Submission:

Published: 梅June 03,2019

Volume 2 - Issue 5

How to cite this article: Zia $A^{*}$, Mehwish A. Fasting in Ramadan and Diabetes. Interventions Obes Diabetes. 2(5). IOD.000550.2019.

DOI: 10.31031/IOD.2019.02.000550

Copyright@ Zia Ashraf, This article is distributed under the terms of the Creative Commons Attribution 4.0 International License, which permits unrestricted use and redistribution provided that the original author and source are credited.

\author{
Zia Ashraf ${ }^{*}$ and Mehwish Ameen ${ }^{2}$ \\ ${ }^{1}$ College of Allied Health Professionals, Pakistan \\ ${ }^{2}$ Punjab Medical College, Pakistan
}

\begin{abstract}
During Ramadan, Muslim community fasts from dawn till sunset. In healthy adults, fasting has no proven harms rather have benefits. Diabetes is a metabolic disorder and may have some consequences while fasting. The aim of our review was to determine, whether or fasting in Ramadan causes any complications in diabetes patients and to search ultimately the advice for management of fast while being diabetic. Ramadan fasting is very much acceptable in patients having type- 2 diabetes which is well managed. Fasting may be allowed to type- 1 diabetes patients with suggestion to monitor their blood glucose level several times a day.
\end{abstract}

\section{Introduction}

Islam has five pillars. Observing Fast in Ramadan is one of the five pillars for adult Muslims worldwide. During fast, eating and drinking is prohibited which is not proven to be harmful for healthy persons [1]. A large survey revealed that $42.8 \%$ type- 1 diabetes and $78.7 \%$ type2 diabetes patients fasted for two weeks [2]. Only few review articles are available on this concern. Original studies were included in this review including control period: i.e. data from control period consisting before and after Ramadan. Studies without involving controls were excluded. Most papers report survey data but very few report original clinical assays. One thing to account for is that Ramadan is a lunar month and happens 10-11 days earlier in every coming year. Which means, after each 9 years, it occurs in different season. The environmental conditions, temperature and length of fasting changes accordingly. This duration was not always cited in most of the studies.

\section{Ramadan fasting: Effects on glycemic status and other biochemical parameters}

Fasting may have increased risks for hypoglycemia due to daytime fasting [3,4], an increase in frequency of hypoglycemia has been reported during fasting in Ramadan both in type- 1 and type-2 diabetes patients [5]. According to some studies Ramadan fasting has been reported to have no effect on glycemic status [2-4,6-11]. There were no significant changes in rhythm of blood glucose in type-2 women [9] Several studies have demonstrated that HbA1C values had no significant change during Ramadan fasting [4,6,7,11-14]. Few studies have reported a decrease in HbA1C level too $[12,15,16]$. There is significant decrease in insulin resistance in males, but it decreases in both genders [14]. Several studies have reported a decrease in triglycerides $[4,17]$. Some studies have shown no significant change in triglycerides, HDL and LDL levels $[9,18,19]$.

\section{Patients on oral hypoglycemic agents}

Several studies have reported on significant effect on glycemic status in type-2 diabetes patients who are treated with OHA [6]. Few studies have reported an increase in hyperglycemic status who took less dose [15].

\section{Patients on insulin treatment}

The effect of insulin was observed in patients with type-1 diabetes observing fast. Glycemic control showed improvement in lispro-insulin as compared to human origin insulin [20]. 


\section{International Diabetes Federation (IDF) and diabetes UK guidelines for Ramadan}

The IDF and diabetes UK have provided proposed three categories of risk for Muslim patients observing Ramadan fast. Those classified into high risk are advised not to fast. Patients on insulin need to make adjustment of dosage. Fasting needs to be interrupted if blood glucose level falls below $70 \mathrm{mg} / \mathrm{dl}$. They provided following recommendations: Screen people for diabetes using locally validated screening methods e.g. HbA1C, blood glucose level. Try to prevent prediabetes with lifestyle modification and increased physical activity. Glucose monitoring is useful during Ramadan. Patients with diabetes should be referred to diabetes training and awareness programs. Overweight and diabetic patients should reduce caloric intake and prefer high fiber diet. Use physician recommended medication and keep proper follow-up [21-23].

\section{References}

1. Roky R, Houti I, Moussamih S, Qotbi S, Aadil N (2004) Physiological and chronobiological changes during Ramadan intermittent fasting. Annals of Nutrition and Metabolism 48(4): 296-303.

2. Benaji B, Mounib N, Roky R, Aadil N, Houti I, et al. (2006) Diabetes and Ramadan: review of the literature. Diabetes research and clinical practice 73(2): 117-125.

3. Benbarka MM, Khalil AB, Beshyah SA, Marjei S, Awad SA (2010) Insulin pump therapy in Moslem patients with type 1 diabetes during Ramadan fasting: An observational report. Diabetes technology \& therapeutics 12(4): 287-290.

4. Sari R, Balci MK, Akbas SH, Avci B (2004) The effects of diet, sulfonylurea, and repaglinide therapy on clinical and metabolic parameters in type 2 diabetic patients during Ramadan. Endocrine research 30(2): 169-177.

5. Salti I, Bénard E, Detournay B, Bianchi BM, Le Brigand C, et al. (2004) A population-based study of diabetes and its characteristics during the fasting month of Ramadan in 13 countries: results of the epidemiology of diabetes and Ramadan 1422/2001 (EPIDIAR) study. Diabetes care 27(10): 2306-2311.

6. Chandalia H, Bhargav A, Kataria V (1987) Dietary pattern during Ramadan fasting and its effect on the metabolic control of diabetes. Practical Diabetes International 4(6): 287-290.

7. Bouguerra R, Jabrane J, Maatki C, Ben LS, Hamzaoui J, et al. (2006) Ramadan fasting in type 2 diabetes mellitus. Annales d'endocrinologie 67(1): 54-59

8. Hemmati M, Karamian M, Malekaneh M (2015) Anti-atherogenic potential of natural honey: Anti-diabetic and antioxidant approaches. J Pharm Pharmacol 3: 278-284.
9. Khatib FA, Shafagoj YA (2004) Metabolic alterations as a result of Ramadan fasting in non-insulin-dependent diabetes mellitus patients in relation to food intake. Saudi medical journal 25(12): 1858-1863.

10. Rashed AH (1992) The fast of Ramadan. BMJ: British Medical Journal 304(6826): 521.

11. Azizi F, Siahkolah B, Shahraz S, Sherafat KR, Zali M, et al. (2003) Ramadan fasting and diabetes mellitus. Arch Iran Med 6(4): 237-242.

12. Sulimani RA, Laajam M, Al-Attas O, Famuyiwa FO, Bashi S, et al. (1991) The effect of Ramadan fasting on diabetes control in type II diabetic patients. Nutrition Research 11(2-3): 261-264.

13. Belkhadir J, El Ghomari H, Klöcker N, Mikou A, Nasciri M, et al. (1993) Muslims with non-insulin dependent diabetes fasting during Ramadan: Treatment with glibenclamide. BMJ 307(6899): 292-295.

14. Yarahmadi S, Larijani B, Bastanhagh M, Pajouhi M, Baradar RJ, et al. (2003) Metabolic and clinical effects of Ramadan fasting in patients with type II diabetes. Journal of the College of Physicians and SurgeonsPakistan: JCPSP 13(6): 329-332.

15. Mafauzy M, Mohammed W, Anum M, Zulkifli A, Ruhani A (1990) A study of the fasting diabetic patients during the month of Ramadan. Med J Malaysia 45(1): 14-17.

16. Gustaviani RR, Soewondo P, Semiardji G, Sudoyo AW (2004) The influence of calorie restriction during the Ramadan fast on serum fructosamine and the formation of beta hydroxybutirate in type 2 diabetes mellitus patients. Acta Med Indones 36(3): 136-141.

17. Athar S (1996) A report on the first international congress on health and Ramadan. J Islamic Med Assoc N Am 28(1): 43-44.

18. Nagati K, Kammoun H, Abid A, Blouza S, Jamoussi H, et al. (2000) Diabetes and fasting during Ramadan: A multicentric Tunisian study. Médecine et Nutrition 36(2): 90-95.

19. Kalantary S, Raja A, Heidarnia B (2001) Blood sugar changes in NIDDM patients in the Ramadan month.

20. Kadiri A, Al-Nakhi A, El-Ghazali S, Jabbar A, Al Arouj M, et al. (2001) Treatment of type 1 diabetes with insulin lispro during Ramadan. Diabetes Metab 27(4 Pt 1): 482-486.

21. Beshyah SA (2016) IDF-DAR practical guidelines for management of diabetes during Ramadan. Ibnosina Journal of Medicine and Biomedical Sciences 8(3): 58-60.

22. Nematy M, Mehdizadeh A (2016) Introducing the practical guideline for diabetes and Ramadan, developed by international diabetes federation in collaboration with diabetes and Ramadan international alliance, 2016. J Fasting Health 4(3): 95-96.

23. Ali S, Davies MJ, Brady EM, Gray LJ, Khunti K, et al. (2016) Guidelines for managing diabetes in Ramadan. Diabetic Medicine 33(10): 1315-1329. 